\title{
State Estimation with Reduced-Order Observer and Adaptive-LQR Control of Time Varying Linear System
}

\author{
Omer Aydogdu ${ }^{1}$, Mehmet Latif Levent ${ }^{2, *}$ \\ ${ }^{I}$ Department of Electrical and Electronics Engineering, Faculty of Engineering and Natural Sciences, \\ Konya Technical University, \\ 42250 Selcuklu, Konya, Turkey \\ ${ }^{2}$ Department of Electrical and Electronics Engineering, Faculty of Engineering, Hakkari University, \\ 30000 Hakkari, Turkey \\ mehmetlatiflevent@hakkari.edu.tr
}

\begin{abstract}
In this study, a new controller design was created to increase the control performance of a variable loaded time varying linear system. For this purpose, a state estimation with reduced order observer and adaptive-LQR (Linear-Quadratic Regulator) control structure was offered. Initially, to estimate the states of the system, a reduced-order observer was designed and used with LQR control method that is one of the optimal control techniques in the servo system with initial load. Subsequently, a Lyapunov-based adaptation mechanism was added to the LQR control to provide optimal control for varying loads as a new approach in design. Thus, it was aimed to eliminate the variable load effects and to increase the stability of the system. In order to demonstrate the effectiveness of the proposed method, a variable loaded rotary servo system was modelled as a time-varying linear system and used in simulations in Matlab-Simulink environment. Based on the simulation results and performance measurements, it was observed that the proposed method increases the system performance and stability by minimizing variable load effect.
\end{abstract}

Index Terms-Adaptation mechanism; Lyapunov method; Reduced-order observer; Time varying linear system.

\section{INTRODUCTION}

Permanent Magnet DC (PMDC) motors, which are frequently preferred since they are easily controlled, have been widely used in recent years. These motors have important features, such as having no use for excitation current, quite low energy consumption owing to the field fluxes they produce, and low costs owing to their small sizes compared to the other motors. In industrial applications, the high performance and stable functioning of the system are two very important criteria. In order to meet these criteria, many different approaches have been used in the literature, such as Proportional-Integral-Derivative (PID) control method [1], [2], sliding mode control [3], [4], FieldProgrammable Gate Array (FPGA) controller [5], adaptive control [6], fuzzy logic controller method [7], [8], and reduced order nonlinear observer [9].

Accurately estimating all unmeasurable states of the system is an important factor that influences the functioning

Manuscript received 19 September, 2019; accepted 29 December, 2019. of the plant in high performance and stability. There are two important methods in state estimation called as "observer" and "Kalman filter". The full order observer method is applied to estimate all states in the controller designs, and the reduced order observer method is applied to estimate unmeasurable states only if there are measurable states. This control structure is used in particularly induction motor control [10] sensorless electric drives [11] permanent magnet synchronous motors [12], linear time-delay systems [13], aircraft motion control [14], and multi-agent systems.

Linear-Quadratic Regulator (LQR) control that aims to minimize the errors that occur in state output value could also be called as "linear optimal state feedback control". This is a method that increases system performance and stability. At the same time, the optimal control input is produced by using controller gain coefficients computed by LQR method. Thus, a response curve close to the desired reference value is obtained. LQR control is used with the Kalman Filter that estimates the real states of the system in noisy environments in state space feedback servo control systems [15], [16].

In this study, the position control of the servo system was employed by using the reduced order observer with LQR control method. However, due to the insufficiency of this method in the variable load environment, a new approach was added to the designed system in order to minimize the effects of the system variable load by adding the Lyapunov stability criterion based adaptation control method. Thus, a new method, the adaptive-LQR method, has been developed. Lyapunov stability criteria, one of the adaptive control methods, is a widely used approach that increases system stability. This method organizes the parameter values based on reference model output value targets to increase the system performance against the destructive effects. Lyapunov-based adaptive control method that is generally more effective on the system performance is preferred in different fields and control mechanisms. Among the applications and the examples of usage area of the Lyapunov-based adaptive control method, there are position control of permanent magnet synchronous motor [17], [18], 
X-Y table experimental platforms control [19], [20], DC motor speed control [21], and the design of a stable and robust tension controller.

In this article, firstly, the modelling of the variable loaded servo system is discussed in Section II. Subsequently, the controller structures used in the study are given in detail. In Section III, the state estimation of the plant through the reduced order observer in a closed loop system is discussed, and in Section IV, the Lyapunov criteria are addressed that provide stability conditions. In Section V, detailed information about the proposed adaptive-LQR control method is conveyed to the relevant researcher. Finally, in Section VI, simulation results are given demonstrating the stability and high performance of the proposed method.

\section{Modelling OF THE VARIABLE LOADED SERVO (VLS) SYSTEM}

As is seen in Fig. 1, a rotary servo system that can alter the load in time was used in the experiments. In industrial applications, Permanent Magnet DC (PMDC) motors are widely used as an actuator for electromechanical energy conversion [22]. It directly provides rotary motion or moment and can provide transitional motion or force when coupled with wheels or drums and cables. The VLS system actuated with PMDC motor, which has the electric circuit of the armature, and the variable loaded body diagram of the rotor are shown in Fig. 1. VLS plant and PMDC motor parameters are given in Table I.

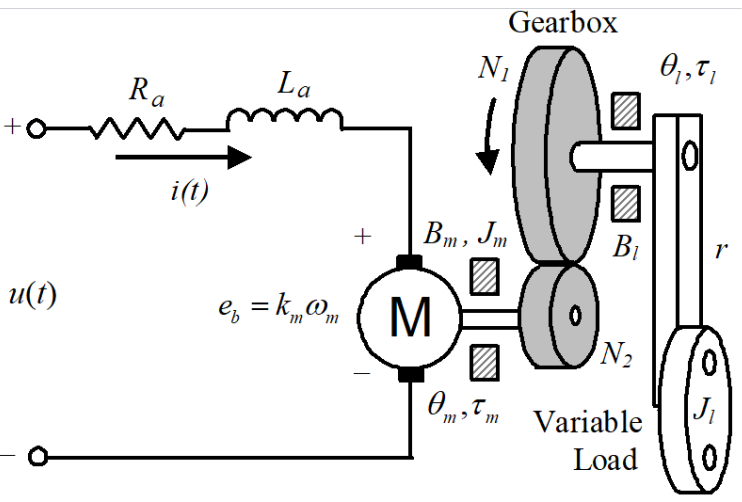

Fig. 1. Equivalent circuit of the VLS system.

The following differential equations can be written based on the Newton's law together with the Kirchhoff's law from the Fig. 1:

$$
\begin{gathered}
u(t)=R_{a} i(t)+L_{a} \frac{d i(t)}{d t}+e_{b}(t), \\
\tau_{m}(t)=J_{m} \frac{d \omega_{m}(t)}{d t}+B_{m} \omega_{m}(t)+\tau_{l}(t), \\
\omega_{m}(t)=\frac{d \theta_{m}(t)}{d t},
\end{gathered}
$$

where $i(t)$ is the armature current, $e_{b}(t)$ is the back ElectroMotive Force (EMF) voltage, $\tau_{m}(t)$ is the produced motor torque, $\tau_{l}(t)$ is the load torque, $\theta_{m}(t)$ is the angle of the armature, and $\omega_{m}(t)$ is the angular velocity of the armature.
The motor torque $\tau_{m}(t)$ is related to the armature current $i(t)$ by a constant factor $k_{t}$, and the back EMF $e_{b}(t)$ is related to the rotational velocity of the armature $\omega_{m}(t)$ by a constant factor $k_{m}$, as given the following equations:

$$
\begin{gathered}
\tau_{m}(t)=k_{t} i(t), \\
e_{b}(t)=k_{m} \omega_{m}(t) .
\end{gathered}
$$

In the VLS system, angular velocity of the load $\omega_{l}(t)$ transmitted by the gearbox from armature velocity $\omega_{m}(t)$ and equivalent armature load torque $\tau_{l}(t)$ may be expressed as:

$$
\begin{gathered}
\omega_{l}(t)=\frac{1}{n} \omega_{m}(t), \\
\tau_{l}(t)=\frac{1}{\eta_{g} n} \tau_{l}^{\prime}(t)=\frac{1}{\eta_{g} n}\left(J_{l} \frac{d \omega_{l}(t)}{d t}+B_{l} \omega_{l}(t)\right), \\
\tau_{l}(t)=\frac{1}{\eta_{g} n^{2}}\left(J_{l} \frac{d \omega_{m}(t)}{d t}+B_{l} \omega_{m}(t)\right),
\end{gathered}
$$

where $n$ is total gear ratio and $\eta_{g}$ is gearbox efficiency. If (8) is substituted in (2), the general moment expression for the motor is obtained as follows

$$
\tau_{m}(t)=\left(J_{m}+\frac{J_{l}}{\eta_{g} n^{2}}\right) \frac{d \omega_{m}(t)}{d t}+\left(B_{m}+\frac{B_{l}}{\eta_{g} n^{2}}\right) \omega_{m}(t)
$$

TABLE I. VARIABLE LOADED SERVO SYSTEM AND LOAD PARAMETERS

\begin{tabular}{|c|c|c|}
\hline Symbol & Definition & Value \\
\hline$u(t)$ & PMDC Motor Voltage & $6 \mathrm{~V}$ \\
\hline$R a$ & Motor armature resistance & $2.6 \mathrm{ohm}$ \\
\hline$L_{a}$ & Motor armature inductance & $0.18 \mathrm{mH}$ \\
\hline$k_{t}$ & Motor torque constant & $0.00767 \mathrm{Nm} / \mathrm{A}$ \\
\hline$k_{b}$ & Motor back-EMF constant & $0.00767 \mathrm{~V} /(\mathrm{rad} / \mathrm{s})$ \\
\hline$n$ & Total gear ratio (N1/N2) & 70 \\
\hline$\eta_{g}$ & Gearbox efficiency & 0.90 \\
\hline$J_{m}$ & Motor inertia & $4.6 \times 10^{-7} \mathrm{~kg} \cdot \mathrm{m}^{2}$ \\
\hline$B_{m}$ & Motor viscous coefficient & $\cong 0(\mathrm{negligible})$ \\
\hline$J_{\text {lin }}$ & $\begin{array}{c}\text { Initial load and gearbox } \\
\text { moment of inertia }\end{array}$ & $4.83 \times 10^{-7} \mathrm{~kg} \mathrm{~m}{ }^{2}$ \\
\hline$J_{\text {lsub }}$ & $\begin{array}{c}\text { Subsequent load and gearbox } \\
\text { moment of inertia }\end{array}$ & $3.41 \times 10^{-3} \mathrm{~kg} \mathrm{~m}{ }^{2}$ \\
\hline$B_{\text {lin }}$ & $\begin{array}{c}\text { Initial load viscous damping } \\
\text { coefficient }\end{array}$ & $4.41 \times 10^{-6} \mathrm{Nm} /(\mathrm{rad} / \mathrm{s})$ \\
\hline$B_{\text {lsub }}$ & $\begin{array}{c}\text { Subsequent load viscous } \\
\text { damping coefficient }\end{array}$ & $4.41 \times 10^{-4} \mathrm{Nm} /(\mathrm{rad} / \mathrm{s})$ \\
\hline
\end{tabular}

The following equations are obtained for the state space expression of the system by using (1), (3)-(5), and (9):

$$
\begin{gathered}
\frac{d i(t)}{d t}=-\frac{R_{a}}{L_{a}} i(t)-\frac{k_{b}}{L_{a}} \omega_{m}(t)+\frac{1}{L_{a}} u(t), \\
\frac{d \omega_{m}(t)}{d t}=\frac{k_{t}}{J_{e q}} i(t)-\frac{B_{e q}}{J_{e q}} \omega_{m}(t),
\end{gathered}
$$




$$
\frac{d \theta_{m}(t)}{d t}=\omega_{m}(t)
$$

where:

$$
\begin{gathered}
J_{e q}=J_{m}+\frac{J_{l}}{\eta_{g} n^{2}}, \\
B_{e q}=B_{m}+\frac{B_{l}}{\eta_{g} n^{2}} .
\end{gathered}
$$

If (10)-(12) are arranged in state space model and armature angle is accepted as the output, the state space expression of the servo system is obtained as (15) and (16):

$$
\begin{gathered}
\dot{x}(t)=A x(t)+B u(t), \\
y(t)=C x(t),
\end{gathered}
$$

where state variables are defined as

$$
x(t)=\left[\begin{array}{c}
x_{1}(t) \\
x_{2}(t) \\
x_{3}(t)
\end{array}\right]=\left[\begin{array}{c}
\theta_{m}(t) \\
\omega_{m}(t) \\
i_{1}(t)
\end{array}\right],
$$

and the state input and output matrices are obtained as:

$$
\begin{gathered}
A=\left[\begin{array}{ccc}
0 & 1 & 0 \\
0 & -\frac{B_{e q}}{J_{e q}} & \frac{k_{t}}{J_{e q}} \\
0 & -\frac{k_{b}}{L_{a}} & -\frac{R_{a}}{L_{a}}
\end{array}\right], \\
B=\left[\begin{array}{c}
0 \\
0 \\
\frac{1}{L_{a}}
\end{array}\right], \\
C=\left[\begin{array}{lll}
1 & 0 & 0
\end{array}\right] .
\end{gathered}
$$

\section{State Estimation WITH REDUCED-ORDER ObSERVER}

The full-order observer is a method that is preferred to estimate all states of the system. Observer design at the degree of $\mathrm{k}^{\text {th }}$ requires for $\mathrm{k}$ number of system states. However, there are both measurable and unmeasurable states in all estimated states. An observer design at $(k-n)$ degree is enough when we assume $n$ number of measurable states for the same system. Reduced-order observer structures are commonly used for system designs that provide ease of operation by reducing the degree of observer.

When a system design is performed and $x_{1}$ that is measurable state and $x_{e}$ that is unmeasurable state, the term of system output $y$, state vector $x$, and partition the state equations are as follow:

$$
\begin{aligned}
& y=x_{1}=C x=\left[\begin{array}{llll}
1 & 0 & \cdots & 0
\end{array}\right] x, \\
& x=\left[\begin{array}{l}
x_{1} \\
x_{e}
\end{array}\right], \\
& {\left[\begin{array}{l}
\dot{x}_{1} \\
\dot{x}_{e}
\end{array}\right]=\left[\begin{array}{ll}
a_{11} & A_{1 e} \\
A_{e 1} & A_{e e}
\end{array}\right]\left[\begin{array}{l}
x_{1} \\
x_{e}
\end{array}\right]+\left[\begin{array}{l}
b_{1} \\
B_{e}
\end{array}\right] u .}
\end{aligned}
$$

There is a need for determining eigenvalues $\left(\mu_{1 e}, \mu_{2 e}, \mu_{3 e}, \ldots, \mu_{(n-1) e}\right)$, which provide stability criterion for defining characteristic equation in the design of an optimum reduced-order observer. Then, the gain matrix calculation $\left(K_{e}\right)$ that is fit for these values is performed:

$$
\begin{gathered}
{\left[\begin{array}{c}
s_{1}=\mu_{1 e} \\
s_{2}=\mu_{2 e} \\
s_{3}=\mu_{3 e} \\
\ldots \\
s_{n-1}=\mu_{(n-1) e}
\end{array}\right],} \\
\left|s I-A_{e e}+K_{e} A_{1 e}\right|=s^{n-1}+\alpha_{(n-2) e^{s}}{ }^{n-2}+\ldots+\alpha_{0 e}, \\
K_{e}=Q_{e}\left[\begin{array}{c}
\alpha_{0 e}-a_{0 e} \\
\alpha_{1 e}-a_{1 e} \\
\vdots \\
\alpha_{(n-2) e}-a_{(n-2) e}
\end{array}\right]
\end{gathered}
$$

where $a_{0 e}, a_{1 e} \ldots a_{(n-2) e}$ values in (27) are the characteristic coefficients of the open loop reduced-order observer:

$$
\begin{gathered}
\left|s I-A_{e e}\right|=s^{n-1}+a_{(n-2) e^{s^{n-2}}+a_{1 e^{s}}+a_{0 e},} \\
Q_{e}=\left(W_{e} N_{e}^{T}\right)^{-1},
\end{gathered}
$$

where:

$$
\begin{gathered}
W_{e}=\left[\begin{array}{ccccc}
a_{1} & a_{2} & \ldots & a_{n-2} & 1 \\
a_{2} & a_{3} & \ldots & 1 & 0 \\
\vdots & & & & \\
a_{n-2} & 1 & \ldots & 0 & 0 \\
1 & 0 & \ldots & 0 & 0
\end{array}\right], \\
N_{e}=\left[A_{1 e}^{T}: A_{e e} T A_{1 e}^{T}: \ldots:\left(A_{e e} T\right)^{n-2} A_{1 e}^{T}\right] .
\end{gathered}
$$

In the first case, $\phi(s)$ is defined as characteristic equation for the closed-loop poles, which we then evaluate for $s=A_{e e}$. Under these circumstances, the equation of Ackermann

$$
K_{e}=\phi\left(A_{e e}\right)\left[\begin{array}{c}
A_{1 e} \\
A_{1 e} A_{e e} \\
\vdots \\
A_{1 e} A_{e e}^{n-3} \\
A_{1 e} A_{e e}^{n-2}
\end{array}\right]^{-1}\left[\begin{array}{c}
0 \\
0 \\
\vdots \\
0 \\
1
\end{array}\right],
$$


where

$$
\phi\left(A_{e e}\right)=A_{e e}^{n-1}+\alpha_{n-2} A_{e e}^{n-2}+\cdots+\alpha_{2} A_{e e}+\alpha_{1} I .
$$

Define reduced estimated states $\dot{\hat{x}}_{e 1}$

$$
\dot{\hat{x}}_{e 1}=\hat{x}-K_{e} y .
$$

Then, all states $\hat{x}$

$$
\hat{x}=\hat{x}_{e 1}+K_{e} y .
$$

Finally, the reduced-order observer equation is given below

$$
\begin{gathered}
\dot{\hat{x}}_{e 1}=\left(A_{e e} K_{e} A_{1 e}\right) \hat{x}_{e 1}+ \\
+\left\{A_{e 1} K_{e} a_{11}+\left(A_{e e}-K_{e} A_{1 e}\right) K_{e}\right\} y+ \\
+\left(B_{e}-K_{e} b_{1}\right) u
\end{gathered}
$$

The block diagram that is fit for this equation is represented in Fig. 2.

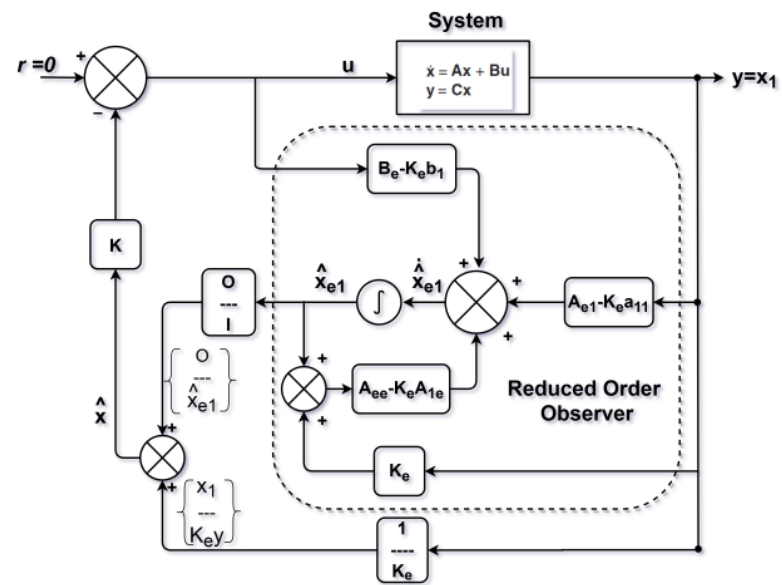

Fig. 2. State estimation with reduced-order observer block diagram.

\section{LYAPUNOV STABILITY CRITERION BASED ADAPTATION MECHANISM}

A large majority of studies about the adaptive control in the literature include "Lyapunov stability" concept. The stable working area of the system and Lyapunov stability criteria are determined by taking the definitions and theories as references.

Let $x$ be a vector; $V(\mathrm{x})$ is scalar function of $x$.

Definition 1: $V(\mathrm{x})$ function is positive definite for states below:

$$
V(x)=0 ; x=0 \text { and } V(x)>0, \forall_{x} \neq 0 .
$$

Definition 2: $V(\mathrm{x})$ function is positive semi-definite for states below:

$$
V(x)=0 ; x=0 \text { and } V(x) \geq 0, x \neq 0 .
$$

Definition 3: $V(\mathrm{x})$ function is negative definite for states below:

$$
V(x)=0, x=0 \text { and } V(x)<0, \forall_{x} \neq 0
$$

Stability status of the system is understood by using following theorems.

Theorem 1: Let us think an equilibrium point. If the neighbors of this point are positive definite $V(\mathrm{x})$ function and negative semi-definite $\dot{V}(\mathrm{x})$ function, this equilibrium point will be stable.

Theorem 2: If the neighbors of this equilibrium point are positive definite and have $V(\mathrm{x})$ function and negative definite $\dot{V}(\mathrm{x})$ function, this equilibrium point is asymptotically stable.

Theorem 3: If the conditions in Theorem 2 are provided and $V(\mathrm{x})$ function is unbounded, the system is globally and asymptotically stable.

\section{V.STATE ESTIMATION WITH REDUCED-ORDER OBSERVER AND ADAPTIVE-LQR CONTROL}

The proposed control structure in the study is given in Fig. 3 below. Initially, the optimal feedback gain matrix values $\mathrm{K}_{l q r}$ for $\mathrm{LQR}$ were obtained from the Riccati equation for the initial load. These obtained LQR gain parameters $\mathrm{K}_{l q r}$ are constant values that do not change over time. Therefore, optimal control is not provided with these $\mathrm{K}_{l q r}$ parameters when the load changes. When Lyapunov stability criterion based adaptation mechanism is added to the system, the state feedback gain matrix values $\left(\mathrm{K}_{\text {new }}\right)$ will change adaptively, i.e. adapt to the environmental conditions in variable load situations.

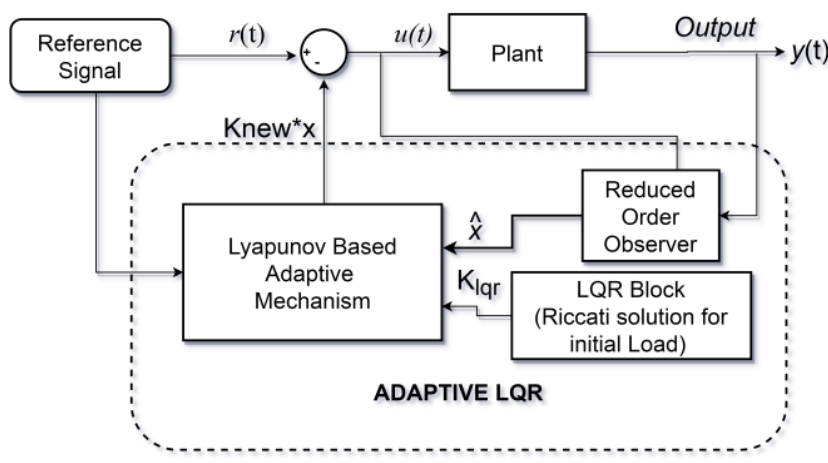

Fig. 3. Adaptive-LQR control block diagram.

Figure 4 shows the block diagram of the Lyapunov based adaptation mechanism. The reference signal $r(\mathrm{t})$, states that are estimated by reduced-order observer, and LQR output that is obtained for initial load are defined as inputs in this related block. In the system, different adaptation blocks for the states that are position $\left(x_{1}\right)$, speed $\left(x_{2}\right)$, and current $\left(x_{3}\right)$ are designed. The first block provides position control; the second block provides speed control, and the third block provides adaptation for the current control. The reference input $r(\mathrm{t})$ is used for the first block and reference input wref data for the second block are defined as the output of the first block. Similarly, the reference input iref of the third block is defined as the output data of the second block. 
In this regard, the purpose of this research is to perform a new adaptive algorithm that ensures optimal state feedback of the system on variable loads. Feedback gain value $K_{n e w}$ in this algorithm that is designed to fit for following equations varies based on the environment conditions.

Hereby, if the gain matrix value at discrete LQR output and the adaptively produced feedback gain value are, respectively, defined as $K_{l q r}=\left[\begin{array}{lll}a_{1} & a_{2} & a_{3}\end{array}\right]$ and $K_{\text {new }}=\left[\begin{array}{lll}b_{1} & b_{2} & b_{3}\end{array}\right]$; update equations of the new adaptive gain matrix value are obtained by using adaptive $u_{1}, u_{2}$, and $u_{3}$ values as follows:

$$
\begin{aligned}
& b_{1}=a_{1}-\frac{u_{1}}{x_{1}}, \\
& b_{2}=a_{2}-\frac{u_{2}}{x_{2}}, \\
& b_{3}=a_{3}-\frac{u_{3}}{x_{3}} .
\end{aligned}
$$

Hereby, the adaptive $u_{1}, u_{2}$, and $u_{3}$ values are separately obtained via model reference adaptive control approach by utilizing the reference model defined below. Adaptive output $u_{1}$ is obtained step by step as above; the similar steps are also applied for $u_{2}$ and $u_{3}$ outputs.

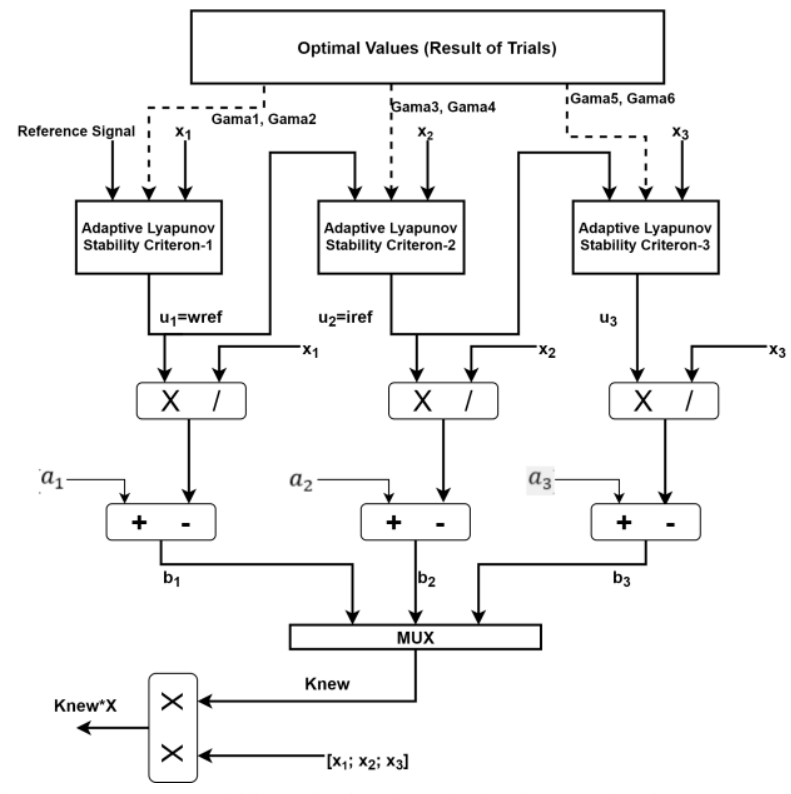

Fig. 4. Lyapunov stability criterion based adaptive mechanism.

By taking the Laplace transformation of (10)-(12), the quadratic transfer function of the servo system is obtained as in (42)

$$
\frac{Y(s)}{U(s)}=\frac{b}{s(s+a)},
$$

where $b$ and $a$ coefficients are obtained as:

$$
b=\frac{k_{t}}{R_{a} J_{e q}},
$$

$$
a=\frac{R_{a} B_{e q}+k_{t} k_{b}}{R_{a} J_{e q}} .
$$

Here, $L_{a}$ is neglected because it is a very small value and it reduces the controller structure for adaptive control by one degree and provides an easy solution.

Accordingly, there is a need to know a quadratic system, a quadratic reference model, and mathematical definitions belonging to the control input based on the controller parameters to make a proper to Lyapunov stability theory. Let us assume that these sentences are defined as reference model in (45), plant model in 46), and adaptive control signal in (47):

$$
\begin{gathered}
\frac{d^{2} y_{m}}{d t^{2}}=-a_{m} \frac{d y_{m}}{d t}+b_{m} r, \\
\frac{d^{2} y}{d t^{2}}=-a \frac{d y}{d t}+b u_{1}, \\
u_{1}=\theta_{1} r-\theta_{2} \frac{d y}{d t} .
\end{gathered}
$$

Here, $\theta_{1}$ and $\theta_{2}$ refer the control parameters, $y$ is the plant output, $y_{m}$ is the reference model output, and $r$ is the reference input signal. Tracking error of the control system is given in (48)

$$
e=y-y_{m}
$$

By subtracting the (45) from (46), we get

$$
\begin{gathered}
\frac{d^{2} e}{d t^{2}}=\frac{d^{2} y}{d t^{2}}-\frac{d^{2} y_{m}}{d t^{2}}=-a \frac{d y}{d t}+b u_{1}- \\
-\left(-a_{m} \frac{d y_{m}}{d t}+b_{m} r\right) .
\end{gathered}
$$

Equation (50) is obtained if (47) is written instead of $u_{1}$ statement in (49). If we add and subtract $a_{m} \frac{d y}{d t}$ statement to both sides of equilibrium in (50)-(54), equations below are obtained. The derivative equation of the error is found in (42) after the required calculations are actualized:

$$
\begin{gathered}
\frac{d^{2} e}{d t^{2}}=-a \frac{d y}{d t}+b\left(\theta_{1} r-\theta_{2} \frac{d y}{d t}\right)+a_{m} \frac{d y_{m}}{d t}-b_{m} r \\
\frac{d^{2} e}{d t^{2}}=-a \frac{d y}{d t}+a_{m} \frac{d y}{d t}+b \theta_{1} r-b \theta_{2} \frac{d y}{d t}-a_{m} \frac{d y}{d t}+ \\
\quad+a_{m} \frac{d y_{m}}{d t}-b_{m} r \\
\frac{d^{2} e}{d t^{2}}=-a_{m}\left(\frac{d y}{d t}-\frac{d y_{m}}{d t}\right)-\left(b \theta_{2}+a-a_{m}\right) \frac{d y}{d t}+ \\
\quad+\left(b \theta_{1}-b_{m}\right) r, \\
\frac{d^{2} e}{d t^{2}}=-a_{m} \frac{d e}{d t}-\left(b \theta_{2}+a-a_{m}\right) \frac{d y}{d t}+\left(b \theta_{1}-b_{m}\right) r,
\end{gathered}
$$




$$
\frac{d e}{d t}=-a_{m} e-\left(b \theta_{2}+a-a_{m}\right) y+\left(b \theta_{1}-b_{m}\right) r .
$$

In (54), the required conditions need to be found for trajectory error to converge to zero. Those conditions are provided by $b \theta_{2}=a_{m}-a$ and $b \theta_{1}=b_{m}$ equations. Control parameters should be well organized to increase system performance. Lyapunov function that is given in (55) is used to obtain the desired parameter values. Lyapunov gain values in this equation are defined by $\gamma_{1}$ and $\gamma_{2}$. Since these gain values are bigger than zero, $b \gamma_{1}>0$ and $b \gamma_{2}>0$ equations are bigger than zero; so, (55), '(56) statement is obtained:

$$
\begin{aligned}
& v\left(e, \theta_{1}, \theta_{2}\right)=\frac{1}{2}\left(e^{2}+\frac{1}{b \gamma_{1}}\left(b \theta_{2}+a-a_{m}\right)^{2}+\right. \\
&\left.+\frac{1}{b \gamma_{2}}\left(b \theta_{1}-b_{m}\right)^{2}\right) \\
& v\left(e, \theta_{1}, \theta_{2}\right)=\frac{1}{2} e^{2}+\frac{\left(b \theta_{2}+a-a_{m}\right)^{2}}{2 b \gamma_{1}}+\frac{\left(b \theta_{1}-b_{m}\right)}{2 b \gamma_{2}} .
\end{aligned}
$$

As is understood from the Section IV, the Lyapunov function needs to be bigger than zero for the system to be stable. Moreover, the derivative of the same function needs to be smaller than zero. Below equation can be obtained when the derivative of (56) that is defined as Lyapunov function is taken

$$
\begin{gathered}
\frac{d v}{d t}=-a_{m} e^{2}-\left(b \theta_{2}+a-a_{m}\right)\left(\frac{d \theta_{2}}{d t}-\gamma_{1} y e\right)+ \\
+\frac{1}{\gamma_{2}}\left(b \theta_{1}-b_{m}\right)\left(\frac{d \theta_{1}}{d t}+\gamma_{2} r e\right) .
\end{gathered}
$$

By reference to (57), the derivative expression of the function becomes smaller than zero if the parameter values are obtained. Accordingly, the stability condition of the system is ensured if the parameters are updated as follows:

$$
\begin{gathered}
\frac{d \theta_{1}}{d t}=-\gamma_{2} r e . \\
\frac{d \theta_{2}}{d t}=\gamma_{1} y e \\
\theta_{1}=\frac{-\gamma_{2}}{s} r e, \\
\theta_{2}=\frac{\gamma_{1}}{s} y e .
\end{gathered}
$$

\section{Simulation Results}

The system proposed for the study and given in Fig. 3 is designed for application in simulation environment, and thus experimental results are obtained. In the first experiment, the load was kept constant at the initial value $\left(J_{\text {lin }}, B_{\text {lin }}\right)$ and was not changed during the test period. The system output responses were obtained separately for the state estimation with reduced-order observer by LQR control system (not included adaptive mechanism) and adaptive-LQR control system. The initial load values are given as $J_{\text {lin }}=4.83 \times 10^{-7} \mathrm{~kg} \mathrm{~m}^{2}, B_{\text {lin }}=4.41 \times 10^{-6} \mathrm{Nm} /(\mathrm{rad} / \mathrm{s})$ in Table I. In this case, the plant parameters $A, B, C$ are obtained as follows:

$$
\begin{gathered}
A=\left[\begin{array}{ccc}
-14444,44 & -42.61 & 0 \\
16670 & -21.73 \times 10^{-4} & 0 \\
0 & 1 & 0
\end{array}\right], \\
B=\left[\begin{array}{c}
5555.56 \\
0 \\
0
\end{array}\right], \\
C=\left[\begin{array}{lll}
0 & 0 & 1
\end{array}\right] .
\end{gathered}
$$

In the second experiment, the load was changed to $J_{l s u b}$ and $B_{l s u b}$ at 21 seconds from the initial load value in the system and the response curve was obtained for reducedorder observer and adaptive LQR system. The variable load values are given as $J_{l s u b}=3.41 \times 10^{-3} \mathrm{~kg} \mathrm{~m}^{2}$ and $B_{l s u b}=4.41 \times 10^{-4} \mathrm{Nm} /(\mathrm{rad} / \mathrm{sec})$ in Table I.

In addition, if we choose the same $R$ and $Q$ parameters for the Kalman filter and LQR control as follows, the LQR gain is found as $K_{l q r}=\left[\begin{array}{lll}1.1036 & 0.9926 & 1\end{array}\right]$.

In the design of the Lyapunov based adaptive control system, a $2^{\text {nd }}$ order system given in (65) is used as a reference model. Here, the reference model has been created in accordance with both settle time and maximum overshoot.

$$
\begin{aligned}
G_{m}(s) & =\frac{40000}{(s+200-i)(s+200+i)}= \\
& =\frac{40000}{\left(s^{2}+400 s+40001\right)} .
\end{aligned}
$$

When adaptive-LQR and reduced order observer with LQR control methods are applied in the system, the results for unvarying system are shown in Fig. 5 and Fig. 6.

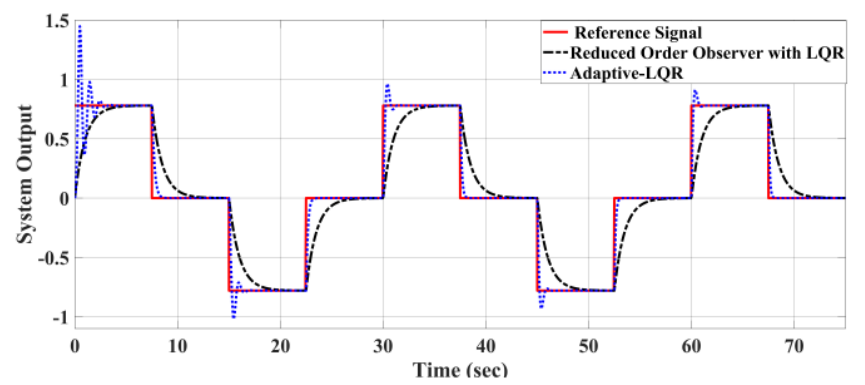

Fig. 5. Proposed control method in unvarying system.

Examining the error change (see Fig. 6), it is concluded that the position output signal rapidly catches the reference signal. As is shown in Table II, comparing the results based on the performance measurements, it is understood that the proposed system produces better results and has a high performance.

One of the most remarkable characteristics of the adaptive state feedback control method is that it compensates the effects, such as variable load. 
TABLE II. PERFORMANCE MEASUREMENT

\begin{tabular}{|c|c|c|c|c|c|c|c|c|c|}
\hline Method & $\gamma_{1}$ & $\gamma_{2}$ & $\gamma_{3}$ & $\gamma_{4}$ & $\gamma_{5}$ & $\gamma_{6}$ & ISE & IAE & ITAE \\
\hline Reduced order observer with LQR & - & - & - & - & - & - & 3.03 & 7.78 & 270.8 \\
\hline Adaptive-LQR & 49.7 & 19.9 & 32.3 & 14.7 & 32.2 & 12.4 & 0.70 & 1.67 & 37.6 \\
\hline
\end{tabular}

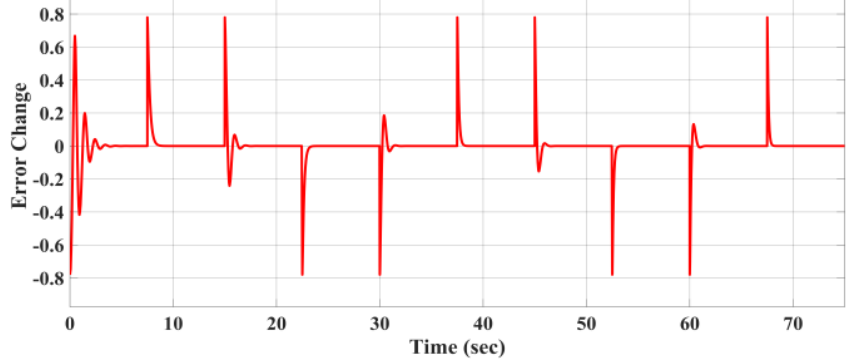

Fig. 6. Proposed control method error change in unvarying system.

The initial load values are changed to $J_{l s u b}=3.41 \times 10^{-3} \mathrm{~kg} \mathrm{~m}^{2}, \quad B_{l s u b}=4.41 \times 10^{-4} \mathrm{Nm} /(\mathrm{rad} / \mathrm{s})$

in the $21^{\text {st }}$ to generate variable load. The responses of the adaptive-LQR and other control method are given in Fig. 7, and effects of the variable load that occured after the $21^{\text {st }}$ second on the response curve of the system is shown in Fig. 8 clearly. Also, change of feedback gain matrix value $K_{n e w}$ is given in Fig. 9 and Fig. 10. Here, it is observed that the gain matrix $K_{n e w}$ value changes in accordance with the environmental conditions and rapidly minimizes the load effects.

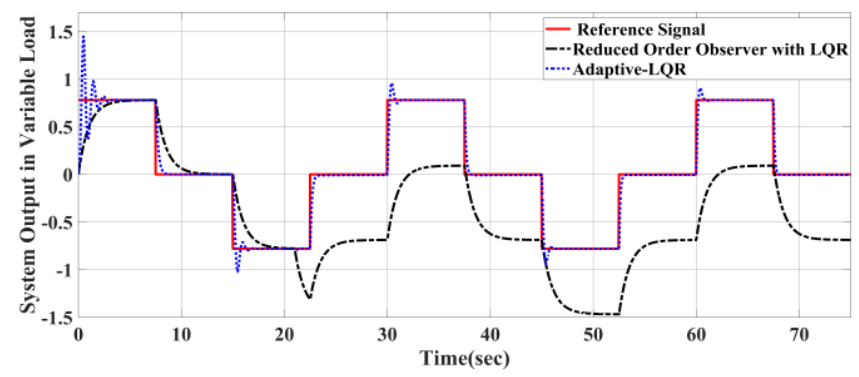

Fig. 7. Proposed method in variable load.

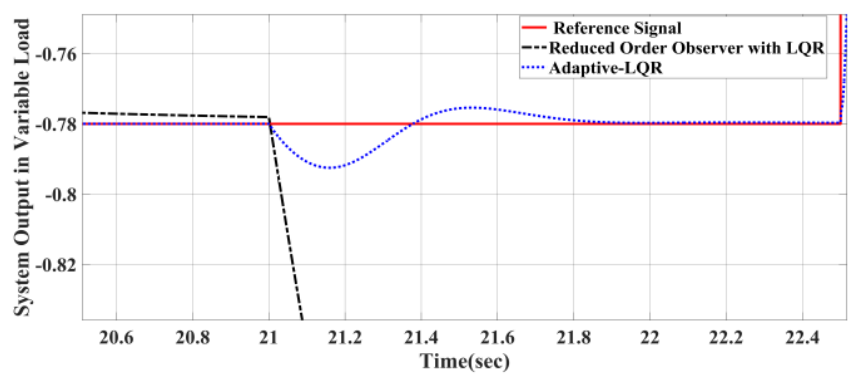

Fig. 8. Zoom area of Fig. 8 (after $t=21^{\text {st }}$ ).

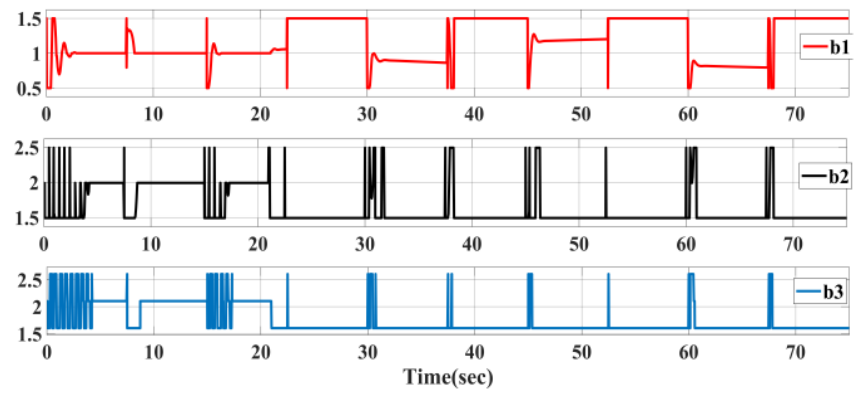

Fig. 9. Change of feedback gain matrix $\left(\mathrm{K}_{\text {new }}\right)$ value.

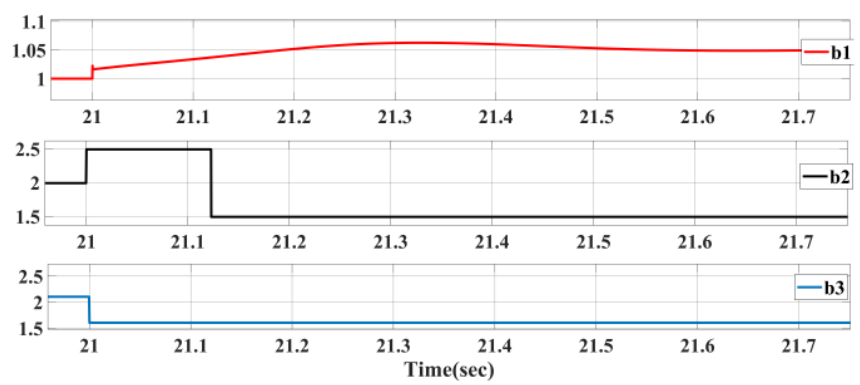

Fig. 10. Zoom area of Fig. $9\left(\right.$ after $\left.t=21^{\text {st }}\right)$.

\section{CONCLUSIONS}

The designed new control system with LQR and reducedorder observer is based on adaptive state feedback control that compensates the disruptive effects, such as variable load and increases the system performance. This controller structure was successfully used in trajectory control of a servo system that can change the load over time in simulation. As is known, it is not possible to completely remove the disruptive effects. The system can estimate the states of the variable loaded servo system, thus the disruptive effects can be minimized. A stable system design that can comply with the environmental conditions was prepared. It is observed on the simulation results that the proposed method gives quite good results in controlling the systems that are exposed to the adverse effects like the variable load. The error between system output response and reference input signal was minimized in time. It is understood from the system results that the system control parameters can adapt itself in time.

\section{CONFLICTS OF INTEREST}

The authors declare that they have no conflicts of interest.

\section{REFERENCES}

[1] E. Moucary, C. Kassem et al., "Complete design of a hardware and software framework for PWM/Discrete PID-based speed control of a permanent-magnet DC motor without prior knowledge of the motor's Parameters", Recent Trends in Computer Applications, pp. 153-173, 2018. DOI: 10.1007/978-3-319-89914-5_10.

[2] Z. Adel, A. A. Hamou, and S. Abdellatif, "Design of real-time PID tracking controller using Arduino Mega 2560 for a permanent magnet DC motor under real disturbance", in Proc. of International Conf. on Electrical Sciences and Technologies in Maghreb (CISTEM), 2018, pp. 1-5. DOI: 10.1109/CISTEM.2018.8613560.

[3] A. Durdu and E. H. Dursun, "Sliding mode control for position tracking of servo system with a variable loaded DC motor", Elektronika ir Elektrotechnika, vol. 25, no. 4, pp. 8-16, 2019. DOI: 10.5755/j01.eie.25.4.23964

[4] R. S. Dhanasekar, K. Ganesh, and R. Marco, "Third order sliding mode control of buck converter fed permanent magnet DC motor", in Proc. of IEEE International Conference on Automation/XXIII Congress of the Chilean Association of Automatic Control (ICAACCA), 2018, pp. 1-4. DOI: 10.1109/ICA-ACCA.2018.8609812.

[5] A. R. Bhavsar and S. V. Patil "Advance speed control technique of permanent magnet brushless DC motor drive using MATLAB simulation and FPGA controller", Proc. of International Conference on Smart Electric Drives and Power System (ICSEDPS), 2018, pp 
388-392. DOI: 10.1109/ICSEDPS.2018.8536003.

[6] H. M. Usman, S. Mukhopadhyay, and H. Rehman, "Permanent magnet DC motor parameters estimation via universal adaptive stabilization", Control Engineering Practice, vol. 90, pp. 50-62, 2019. DOI: $10.1016 /$ j.conengprac.2019.06.006.

[7] L. Abirami, A. Tamizhselvan, V. Rajini, and S. Sinthamani, "Speed control of permanent magnet DC motor using bridgeless rectifier based fuzzy controller", International Journal of Pure and Applied Mathematics, vol. 119, pp. 1165-1172, 2018.

[8] Z. Tir, M. A. Hamida, H. Cherif, Y. Bekakra, and A. Kadrine, "Implementation of a fuzzy logic speed controller for a permanent magnet dc motor using a low-cost Arduino platform", in Proc. of 5th International Conference on Electrical Engineering-Boumerdes (ICEE-B), 2017, pp. 1-4. DOI: 10.1109/ICEE-B.2017.8192218.

[9] H. Chu, B. Gao, W. Gu, and H. Chen, "Low-speed control for permanent-magnet DC torque motor using observer-based nonlinear triple-step controller", IEEE Transactions on Industrial Electronics, vol. 64, pp. 3286-3296, 2016. DOI: 10.1109/TIE.2016.2598298.

[10] K. Y. Chen, W. H. Yang, and R. F. Fung, "System identification by using RGA with a reduced-order robust observer for an induction motor", Mechatronics, vol. 54, pp. 1-15, 2018. DOI: 10.1016/j.mechatronics.2018.07.001.

[11] Y. Zhao, W. Qiao, L. Wu, "Position extraction from a discrete sliding-mode observer for sensorless control of IPMSMs", in Proc. IEEE Int. Symposium on Industrial Electronics (ISIE), 2012, pp. 725-730. DOI: 10.1109/ISIE. 2012.6237159.

[12] J. Yu, Y. Ma, H. Yu, and C. Lin, "Reduced-order observer-based adaptive fuzzy tracking control for chaotic permanent magnet synchronous motors", Neurocomputing, vol. 214, pp. 201-209, 2016. DOI: 10.1016/j.neucom.2016.05.088.

[13] W. B. Seifeddine, O. Boubaker, M. Lungu, and S. Mobayen, "Full and reduced-order unknown input observer design for linear timedelay systems with multiple delays", Mathematical Problems in Engineering, pp. 1-13, 2018. DOI: 10.1155/2018/1745734.

[14] M. Lungu and R. Lungu, "Reduced-order multiple observer for aircraft state estimation during landing", Applied Mechanics and
Materials, vol. $\quad 841$, pp. 253-259, 2016. DOI: 10.4028/www.scientific.net/AMM.841.253.

[15] S. Tunyasrirut, V. Kinnares, and J. Ngamwiwit, "Performance improvement of a slip energy recovery drive system by a voltagecontrolled technique", Renewable Energy, vol. 35, no. 10, pp. 22352242, 2010. DOI: $10.1016 /$ j.renene.2010.02.015

[16] Y. Zhi, G. Li, Q. Song, K. Yu, and J. Zhang, "Flight control law of unmanned aerial vehicles based on robust servo linear quadratic regulator and Kalman filtering", International Journal of Advanced Robotic Systems, vol. 14, pp. 1-7, 2017. DOI: $10.1177 / 1729881416686952$.

[17] F. J. Lin, S. G. Chen, and I. F. Sun, "Adaptive backstepping control of six-phase PMSM using functional link radial basis function network uncertainty observer", Asian Journal of Control, vol. 19, pp. 22552269, 2017. DOI: 10.1002/asjc. 1521.

[18] F.-J. Lin, I.-F. Sun, K.-J. Yang, and J.-K. Chang, "Recurrent fuzzy neural cerebellar model articulation network fault-tolerant control of six-phase permanent magnet synchronous motor position servo drive", IEEE Transactions on Fuzzy Systems, vol. 24, no. 1, pp. 153 167, 2015. DOI: 10.1109/TFUZZ.2015.2446535.

[19] H. Wang, X. Zhao, and Y. Tian, "Trajectory tracking control of XY table using sliding mode adaptive control based on fast double power reaching law", Asian Journal of Control, vol. 18, pp. 2263-2271, 2016. DOI: $10.1002 /$ asjc. 1322

[20] W.-L. Mao, Ch.-W. Hung, and Suprapto, "Adaptive fuzzy trajectory control for biaxial motion stage system", Advances in Mechanical Engineering, vol. 8, pp. 1-16, 2016. DOI: $10.1177 / 1687814016645443$.

[21] B. Rashidi, M. Esmaeilpour, and M. R. Homaeinezhad, "Precise angular speed control of permanent magnet DC motors in presence of high modeling uncertainties via sliding mode observer-based model reference adaptive algorithm", Mechatronics, vol. 28, pp. 79-95, 2015. DOI: 10.1016/j.mechatronics.2015.04.009.

[22] O. Alkan and O. Aydogdu, "Fuzzy model reference learning control of a time-varying rotary servo systems", in Proc. of Second International Conference on Informatics, 2011, pp. 1-6. 